\title{
Compromisso tardio da sociedade com a escola e o professor
}

Roseli Fígaro

Professora livre-docente do programa de pós-graduação em Comunicação e Coordenadora do Centro de Pesquisa em Comunicação e Trabalho (CPCT-ECA-USP)

E-mail: figaro@uol.com.br

Resumo: A partir de perspectiva histórica, a autora faz breve relato da tardia universalização da educação no Brasil. Além de apresentar problemas e contradições na formação de alunos e professores, há a falta de reconhecimento do valor do professor na sociedade brasileira, fator que acarreta baixos salários e péssimas condições de trabalho. Como avanços, há atualmente a implantação de um conjunto de diretivas de políticas públicas, voltadas para a melhoria do ensino, garantia de acesso ao ensino básico e apoio à formação continuada de professores, entre outros. Tais políticas precisam ser consolidadas, avaliadas e aperfeiçoadas, pois o professor é um mediador do processo de aprendizado e, como parte de sua formação, é preciso incluir de maneira assertiva e coerente os conteúdos relativos ao campo da comunicação.

Palavras-chave: escola; educação; professor; políticas públicas; universidades.
Abstract: From a historical perspective, the author outlines a brief account of the late universalization of education in Brazil. Besides presenting the problems and the contradictions in the education of students and teachers, there is the lack of recognition for the teachers and their work in Brazilian society, leading to low wages and poor working conditions. As advancements, there is the current development of a set of public policies aimed at the education improvement, at the assurance for elementary education and at the support for continuing teacher education, among others. Such policies need to be consolidated, evaluated and improved, because the teacher is a facilitator of the learning process and as part of his/her formation, it is necessary to include assertively and consistently the content related to the field of communication.

Keywords: school; education; teacher; public policies; universities.

A escola é uma conquista da sociedade moderna, um chamamento à razão, que indica a necessidade de a sociedade ocupar-se da formação das novas gerações; tem como fundamento a liberdade do indivíduo, o ensino laico, o desenvolvimento científico e a democracia. A história da escola, como a conhecemos, é recente. As famílias dos nobres e cidadãos abastados contratavam intelectuais e artistas para educarem os seus filhos. Sócrates, Platão, Aristóteles foram alguns desses filósofos educadores. Embora a ideia de escola possa ser encontrada na obra República, de Platão, e também Aristóteles tenha fundado sua própria Academia, a ideia de escola como direito de todo cidadão começa a aparecer depois da Revolução Francesa, ou seja, em meados do século XVIII. 
A escola é instituída no Ocidente pelo Estado burguês, laico e republicano como forma de instrução para o homem comum. Conforme esclarece Rodriguez ${ }^{1}$, Marie Jean Antoine Nicolás de Caritat, Marquês de Condorcet, foi Presidente do Comitê de Instrução Pública, na França revolucionária e, como tal, defendeu que a educação fosse estendida a todas as classes de cidadão. Muitas de suas ideias foram influenciadas, sobretudo, por Jean Jacques Rousseau. Condorcet defendeu o papel do Estado na instrução laica do cidadão, e essa instrução deveria potencializar o indivíduo, preparando-o para gerir seus interesses com responsabilidade perante o outro, guiado pela razão. No entanto, "durante o governo de Napoleão, o projeto do Marquês foi abandonado totalmente. A instrução acabou ficando sob o controle do Clero e o ensino médio adotou uma orientação clássica"2.

Essas são conquistas burguesas que só começaram a chegar ao Brasil em meados do século XIX, embora o Marquês de Pombal tenha tentado, no século XVIII, depois da expulsão dos Jesuítas, instalar por aqui um modelo Iluminista de escola. Até o final da escravidão e da monarquia, o tema da escola, no Brasil, é restrito às famílias de posses. A República, a vida urbana e a imigração de populações brancas da Europa para o país criam uma nova realidade e o desafio de o Estado responder às demandas pela educação. É preciso formar para o trabalho, preparar as novas gerações para a vida urbana.

Conquanto se tenha avançado, chegamos às décadas finais do século XX com parcela expressiva de analfabetos e com crianças sem acesso à escola. É somente a partir da Constituição de 1988 que a universalização do ensino se tornaria política pública.

\section{POLÍTICAS PÚBLICAS: ESCOLA E PROFESSOR}

A Constituição de 1988, em seu artigo 22, estabelece que é papel exclusivo da União legislar sobre as diretrizes e bases da educação nacional. Dessa orientação decorre a Lei de Diretrizes e Bases - LDB, que entra em vigor em 1996 e traça os objetivos para a educação nacional.

Nesse percurso, muitos embates têm sido travados pela sociedade civil em prol da regulamentação da legislação necessária para a articulação de um Sistema Nacional de Ensino capaz de colocar em sintonia a federação, os esta-

1. RODRIGUEZ, Margarita Victória. A origem da escola moderna: o legado de Condorcet. Acta Scientiarum. Education, Maringá, v. 32 n. 1, p. 67-74, 2010. DOI: 10.4025/actascieduc. v32i1.9771. p. 67. Disponível em: <http://periodicos.uem.br/ojs/index php/ActaSciEduc/article/ download/9771/9771>.

2. Ibid., p. 68 . dos e os municípios. Quem perde com a falta desse sistema integrado, gerido por políticas públicas capazes de efetivamente nortearem a ação dos agentes governamentais, é a população que depende do sistema público para ter acesso à educação.

Outro documento relevante, no sentido de dar diretrizes nacionais para a educação, é o Plano Nacional de Educação (2001-2008), Lei n. 10.172, de 9 de janeiro de 2001. O PNE determina diretrizes para a Educação Básica (ensino fundamental e médio), para outras Modalidades de Ensino (educação de jovens e adultos, indíos), para a Formação dos professores e valorização do magistério, entre outras diretivas. No processo de avaliação de sua implantação, realizado 
em 2009, no que diz respeito à formação de professores e valorização do magistério, é notório que os resultados ainda não chegam a contento.

Com a expansão do ensino básico, escancara-se o que todos já sabiam: não há profissionais preparados para atender a toda a demanda. As políticas de formação continuada de professores, de formação de novos licenciados e de capacitação daqueles que estão em exercício, mas não têm curso superior, ainda não são suficientes para preencher a lacuna existente. Precisam ser ampliadas e qualificadas.

Com relação à formação do professor licenciado, a maior parte deles é proveniente das camadas populares. Classes que chegam tarde à escola e mais ainda ao ensino superior. Massificar o ensino superior significa, no Brasil, ampliar a oferta por meio de políticas de incentivo e de reconhecimento de novas instituições de ensino superior privadas. Essas medidas se, por um lado, mostram-se capazes de atender à demanda reprimida de interessados, de outro, deixa a desejar com relação à qualidade de ensino que oferece para a formação do profissional.

A contradição é acachapante: na Universidade pública de melhor qualidade, ingressam, por mérito, os jovens mais bem preparados. Na Instituição de Ensino Superior privada, paga a preços módicos, ingressam os jovens trabalhadores, oriundos do ensino básico público de menor qualidade. A maior parte dos professores que exercem a profissão é proveniente dessas instituições de ensino superior privadas.

Há ainda um fator complicador, a sociedade brasileira não reconhece o valor profissional do professor. É uma profissão a que poucos recorrem. Os salários são péssimos e as condições de trabalho - escolas distantes, salas com mais de 35 alunos, número de horas/aula elevado, trabalho em várias escolas - impedem que os vocacionados desempenhem um bom trabalho. Além desses elementos relativos à profissão, são transferidos à escola problemas que não lhe pertencem: violência urbana, desintegração familiar, carência alimentar e de saúde etc.

\section{AVANÇOS, LIMITAÇÕES E DESAFIOS}

Mas há avanços. O Fundo Nacional de Desenvolvimento da Educação Básica e de Valorização do Magistério - Fundeb - destina 60\% de seus recursos para a remuneração dos professores e para a criação de plano de carreira. Essa medida também estabelece o piso salarial nacional, Lei n. 11.494/07, embora ainda não seja cumprida na maioria dos estados da federação.

Outro dado de política pública relevante é o Programa de formação continuada de professores e professores alfabetizadores. O Programa atende os professores das redes estaduais e municipais e está implantado em larga escala. Os cursos são oferecidos na modalidade a distância e ainda não se tem ao certo seu impacto na melhoria da qualidade do ensino.

Outro fato demonstrativo do avanço, com relação à consciência da sociedade civil sobre a necessidade do desenvolvimento democrático da educação 
no Brasil, foi a realização da CONAE - Conferência Nacional de Educação que aprovou, em 2010, as diretrizes para o Plano Nacional de Educação 2011-2020. Um dos principais desafios que se formulou como tarefa foi o reconhecimento do professor por meio de remuneração adequada à responsabilidade da profissão.

Como se vê, na primeira década do século XXI, o Brasil implanta um conjunto de diretivas de políticas públicas voltadas para a melhoria do sistema de ensino, garantia de acesso ao ensino básico e apoio à formação continuada para os professores, formulação de política nacional de melhoria salarial e quadro de carreira para os trabalhadores da educação. Essas políticas precisam ser consolidadas e constantemente avaliadas no sentido de seu aperfeiçoamento.

Começa a se estabelecer um consenso sobre a necessidade de ampliação da atenção e dos recursos para a valorização da profissão de professor. Passo concomitante precisa ser dado com relação à atualização dos currículos dos cursos de licenciatura e passo maior para que se compreenda que o professor é um mediador do processo de aprendizado; sua figura é fundamental e, como parte de sua formação, é essencial incluir de maneira assertiva e coerente os conteúdos relativos ao campo da comunicação.

\section{ARTIGOS NACIONAIS}

$\mathrm{O}$ artigo Fotografia de crianças e seus personagens midiáticos: contribuições para pensarmos as práticas educomunicativas no contexto educacional contemporâneo, de Ademilde Silveira Sartori, Patrícia Justo Moreira e Kamila Regina de Souza, discute como a fotografia pode revelar a relação da criança com os produtos culturais e as narrativas dos heróis midiáticos. As autoras entendem que "as práticas pedagógicas educomunicativas [...] revelam importantes contribuições no que se refere às novas demandas da escola nesta contemporaneidade marcada pela forte presença das referências midiáticas".

O fazedor e as ferramentas de pensar, artigo de Hila Rodrigues, Marta Maia e Ricardo Lima, trata do ensino universitário de jornalismo, destacando a relevância da formação profissional de ampla base cultural humanística, porque, para os autores, "O jornalista é um fazedor de realidades, que, ante a dificuldade de criá-la, precisa estudar a 'ciência' e adquirir perícia nas formas de fazer surgir um mundo inteligível e verossímil”.

Os autores Rosa Maria Cardoso Dalla Costa e Luis Otávio Dias, no artigo TV Multimídia: uma tela de oportunidades para a Educomunicação nas escolas públicas do Paraná, discutem a tevê como espaço multimídia repleto de oportunidades para o trabalho em sala de aula. Eles partem do pressuposto de que: "Há um consenso entre pesquisadores e estudiosos de que a escola tornou-se um campo vasto para a pesquisa em comunicação, aberta a novas possibilidades de investigação, experimentações e de mediações". A criatividade e o trabalho atento do professor podem transformar o material que se apresenta na tevê em objeto de estudo, pesquisa e crítica na sala de aula. 
Compromisso tardio da sociedade com a escola e o professor - Roseli Fígaro

Em tempos de controle de e-mails, imagens, arquivos e conversas que trafegam nos servidores das nove grandes empresas de Internet (Microsoft, Apple, Google, Facebook, Skype, Yahoo, YouTube, AOL e PalTalk), pela Agência de Segurança Nacional e o FBI norte-americanos, o artigo Liberdade de expressão: como lutar por ela, de Maria Cristina Castilho Costa, é de enorme importância. Pensamos e agimos como se a censura à liberdade de expressão fosse prerrogativa de ditadores, e esquecemos muitas vezes que o sistema econômico e os interesses geopolíticos das classes dominantes gerenciam e monitoram a sociedade. Segundo a autora, "professores, jornalistas, artistas em geral, escritores, editores, produtores culturais são os que se mobilizam em defesa da liberdade de expressão"; isso é importante e espera-se que os professores mais uma vez façam valer sua missão de educar as novas gerações para a liberdade.

\section{ARTIGOS INTERNACIONAIS}

No artigo A aposta universitária espanhola nas novas figuras profissionais em rede, Hada M. Sánchez Gonzales e Sandra Méndez Muros discutem a presença preponderante das mídias digitais e das redes sociais nas rotinas produtivas jornalísticas, e como as universidades espanholas estão se preparando para a formação do profissional. As autoras realizam pesquisa nos currículos de universidades públicas e privadas sobre a oferta de disciplinas vinculadas às tecnologias de Internet e às redes sociais.

Em The Special One. Fenomenologia do herói desportivo, o professor da Universidade de Coimbra, Carlos Reis, discute o futebol, a partir da fabricação de seus heróis midiáticos; um tema obrigatório, sobretudo, em 2014, ano da Copa do Mundo. Para o autor: "Os heróis [...] são figuras tão massificadas como os veículos e os discursos mediáticos que fazem do futebol uma presença quase obsessiva no nosso quotidiano, assim projetando sobre ele aqueles atributos”.

\section{GESTÃO DA COMUNICAÇÃO}

Tatiana Douchkin, no artigo Programa Universidade Aberta à Terceira Idade da Universidade de São Paulo: aspectos comunicacionais, analisa "sob a perspectiva da Gestão da Comunicação [...] o intercâmbio de informações entre as gerações da graduação e da terceira idade", e relata-nos como o Programa permite ao idoso aprofundar conhecimentos em áreas de seu interesse.

\section{ENTREVISTA}

Giselle Beiguelman, uma pensadora da contemporaneidade é o título da entrevista realizada por Cláudia Nonato com a midiartista, pesquisadora e professora da Faculdade de Arquitetura e Urbanismo da USP Giselle Beiguelman. A professora 
comunicação \& educação • Ano XVIII • número 2 • jul/dez 2013

dedica-se às complexas relações existentes entre literatura e novos meios, faz pesquisa com plataformas digitais e wireless, bem como direciona suas preocupações às novas gerações e ao uso das tecnologias.

\section{CRÍTICA}

Em A transmidialidade em Morde \& Assopra: uma reflexão sobre consumo cultural e construções narrativas, Maria Aparecida Baccega e Andréa Antonacci discutem a construção narrativa na formatação do gênero televisivo em contexto transmidiático. Os objetos da crítica são a telenovela Morde \& Assopra e o blog Caçadora de Dinossauros, ambos da Rede Globo.

\section{DEPOIMENTO}

É com muito respeito e orgulho que publicamos o depoimento da professora Ecléa Bosi, pesquisadora e artesã das narrativas de memórias. Ela própria uma eximia narradora, que nos arrebata com sua fala/escrita mansa, densa, carinhosa. Ecléa Bosi: formando o olhar de testemunhas do presente é o título que demos ao depoimento da Professora.

\section{EXPERIÊNCIA}

A produção narrativa das crianças no contexto das mídias, de Gilka Elvira Ponzi Girardello e Karin Cozer de Campos, é o relato sobre a produção narrativa de crianças que contam suas experiências com as mídias em rodas de história.

\section{POESIA}

Adilson Citelli escolheu para este número homenagear o poeta, crítico, ensaísta e professor Mário Chamie. Em Mário Chamie: o poeta em busca de novas formas de comunicação, desfrutamos de poesias publicadas no livro Lavra, Lavra, de 1962.

\section{RESENHAS}

Telenovela brasileira: consumo e transmidiação é o título da resenha que Ligia Maria Prezia Lemos faz do livro Consumindo e vivendo a vida: telenovela, consumo e seus discursos, obra organizada por Maria Aparecida Baccega e Maria Isabel Rodrigues Orofino, com artigos de pesquisadores de Comunicação e Práticas de Consumo.

Já Maria Ignês Carlos Magno, em Contra o esquecimento. Cinema e política atravessados pelas memórias da infância nos filmes, nos propõe um olhar atento aos 
filmes: El premio (2011) e $O$ ano em que meus pais saíram de férias (2006). Ambos não nos deixam esquecer de nossa história recente: os anos de chumbo na Argentina e no Brasil.

Em Imagem, uma janela para a Educomunicação, Ismar de Oliveira Soares comenta a relevância dos livros: Educação, imagem e mídias, de Maria Cristina Castilho Costa, e Mídias e mediação escolar: pedagogia dos meios, participação e visibilidade, de Maria Isabel Rodrigues Orofino. Ambos, segundo Soares, apontam para a importância que o tema do audiovisual vem adquirindo para a área da Educomunicação.

\section{ATIVIDADES EM SALA DE AULA}

Ruth Ribas Itacarambi sugere atividades a serem desenvolvidas pelos professores, dirigidas aos alunos de ensino fundamental e médio, a partir dos artigos deste número de Comunicação Ė Educação. O desafio é articular temas e formatos, apresentados nesta edição, aos conteúdos curriculares de cada nível e série.

Bom trabalho! 


\section{Curso de Especialização em Educomunicação

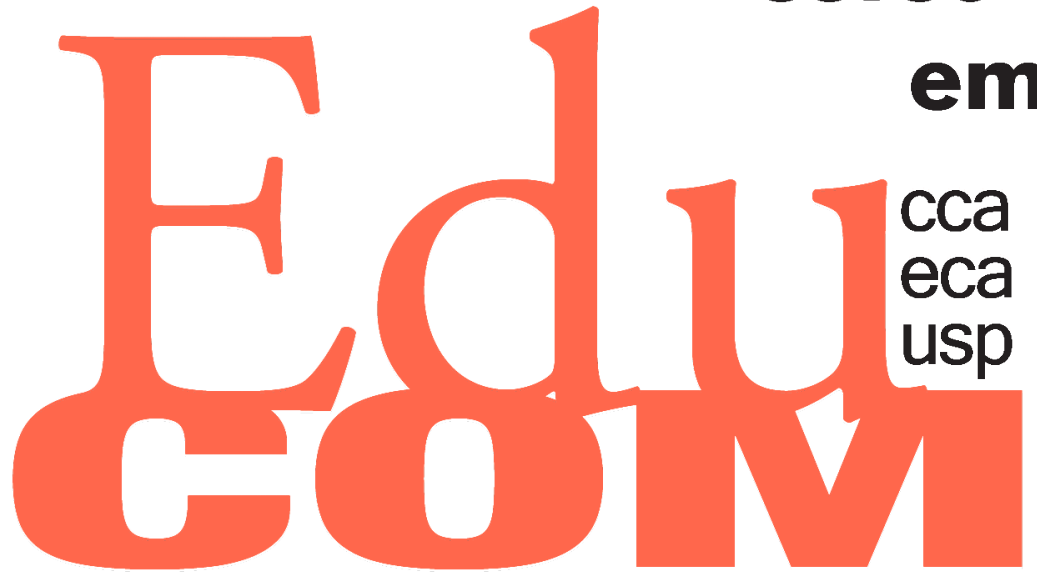 \\ curso de especialização lato sensu}

\section{O Departamento de Comunicações e Artes da ECA/USP abre inscrições} para nova turma de especialização lato sensu em Educomunicação

\section{Habilidades do Educomunicador}

- Desenvolver uma leitura crítica da mídia.

- Dominar a pedagogia do tratamento da comunicação no espaço escolar, tanto como conteúdo didático quanto como processo a ser adotado.

- Ampliar o coeficiente comunicativo das ações educativas, garantindo as diferentes formas de expressão por parte dos polos vivos no ecossistema escolar, valorizando especialmente a mediação artística.
- Implementar trabalhos colaborativos de produção midiática utilizando os recursos da informação e da comunicação em processos educativos.

- Implementar estratégias de planejamento, gestão e avaliação de planos, programas e projetos na área da comunicação/ educação em espaços educativos.

- Entender e interferir nas políticas públicas que legitimam a educomunicação como nova área de intervenção social nos espaços educativos.

\section{Processo Seletivo Semestral}

Duração: três semestres

Pré-requisito: formação superior em

$$
\text { qualquer área do saber. }
$$

Seleção: prova escrita, entrevista

\section{Mais informações www.cca.eca.usp.br}
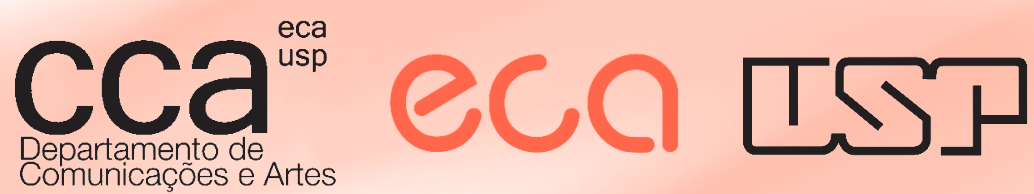

Endereço

Av. Prof. Lúcio Martins

Rodrigues, 443, sl 209

Cidade Universitária

São Paulo - SP

\section{Contato}

(+5511) 3091-4341

(+5511) 3091-4867

www.cca.eca.usp.br 


\section{A teoria da conunicr em prática

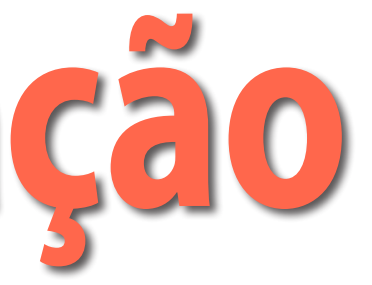

Por um comunicador afinado com as técnicas, mas, principalmente, atento ao importante papel dos meios de comunicação na construção de um mundo ético e justo,

possível apenas se os valores cristãos forem os elementos norteadores de seu trabalho.

Para o profissional ou amador, para o leigo ou religioso, gente que quer exercer a comunicação de forma atuante e comprometida, obras trazem conceitos, dicas, orientações e exemplos práticos para a produção nas diferentes áreas, aplicáveis tanto em ambientes profissionais quanto em escolas, associações, centros comunitários, paróquias etc.
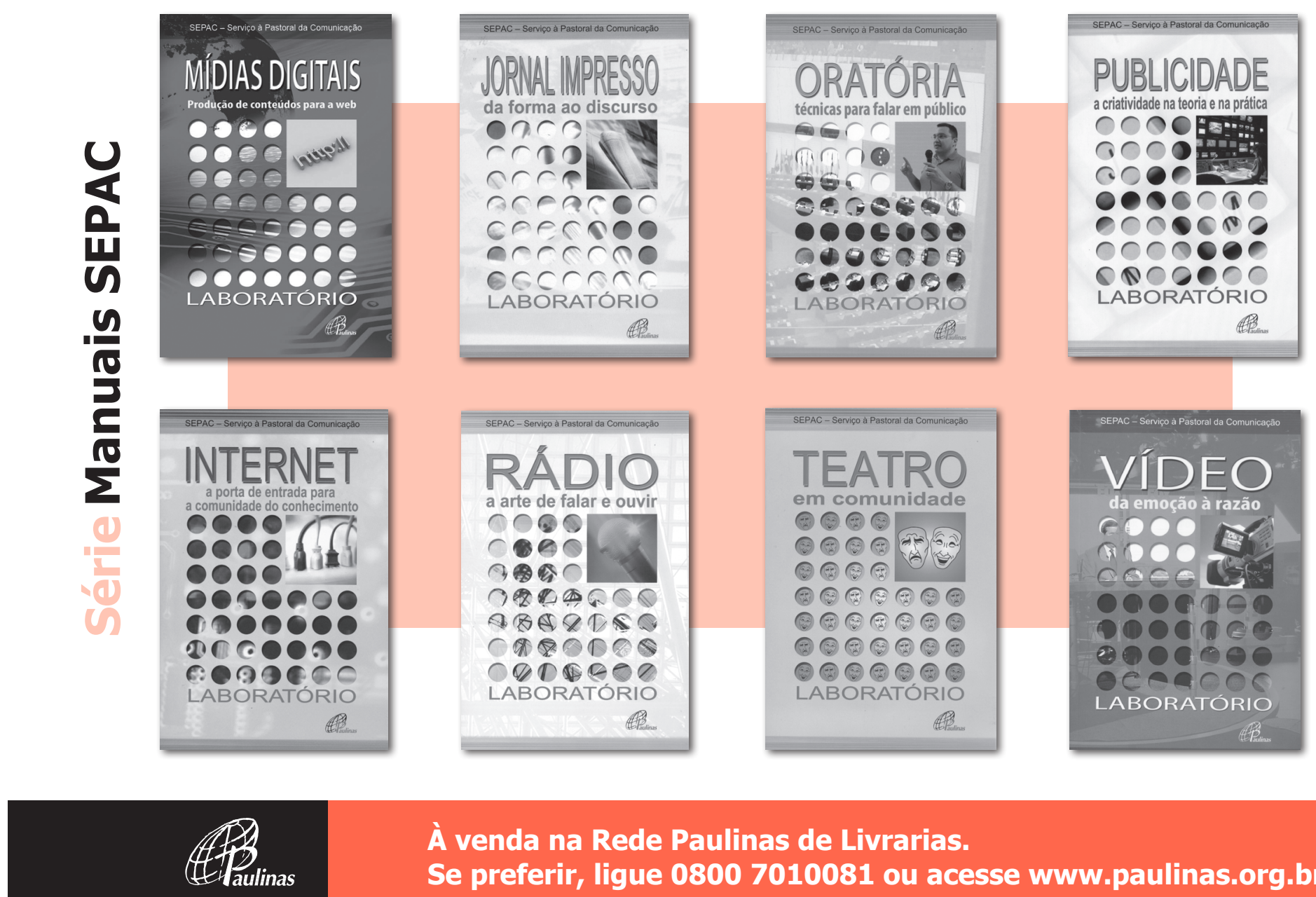

À venda na Rede Paulinas de Livrarias.

Se preferir, ligue 08007010081 ou acesse www.paulinas.org.br 


\section{बृत

A Revista Comunicação E̊ Educação é uma publicaşão semestral (janeiro/junho; julho/dezembro) na área da comunicação $e$ educação. Além disso, a Revista, hoje, é um dos principais veículos de estudo e pesquisa no campo da educomunicação.

Os artigos são recebidos em fluxo contínuo, isto é, recebemos textos em qualquer período do ano por meio do endereço eletrônico <http://revistas.usp.br/comueduc/index >.

São aceitos artigos originais e inéditos de doutores. Serão aceitos artigos de mestrandos e mestres desde que em coautoria com um doutor.

Os textos apresentados em congressos, simpósios e seminários são aceitos, com a condição de estarem estruturados em forma de artigos, serem inéditos e estarem de acordo com as normas de publicação.

A Revista não é temática, a pauta é feita de acordo com o tema das colaborações recebidas. REQUISITOS TÉCNICOS

Os títulos devem ser curtos, e a intertitulação é necessária.

$\mathrm{O}$ artigo, no início do texto, deve ter resumo e abstract com no máximo 10 e no mínimo 8 linhas.

Sob o resumo, deverá haver 5 palavras-chave.

Tanto o resumo como as palavras-chave devem estar em português e inglês.

Cada artigo deverá ter no máximo 25 mil e no mínimo 15 mil caracteres com espaço.

Fonte: times new roman, corpo 12, entrelinhas com espaço 1,5.

Inserir número de página no fim da folha.

Tamanho no papel: A4 $(2,10 \times$ x 2,97 cm), com orientação retrato, margens superior, inferior, esquerda e direita de $2,5 \mathrm{~cm}$.

Normas: ABNT.

CITAÇÕES

As citações devem ser em notas de rodapé. Exemplo:

AUGÉ, Marc. A Guerra dos Sonhos. Campinas (SP): Papirus, 1998, p. 80. REFERÊNCIAS BIBLIOGRÁFICAS

É necessário apenas repetir a referência geral, sem o número da página. Exemplo:

AUGÉ, Marc. A Guerra dos Sonhos. Campinas (SP): Papirus, 1998.

O referencial bibliográfico deverá ter no máximo 2 páginas.

ILUSTRAÇÕES

Imagens (figuras e fotos): devem ser nítidas, no tamanho máximo de $9 \times 14 \mathrm{~cm}$, apresentadas em formato digital padrão JPEG em 300dpi; devem ser centralizadas no documento e conter legendas.

Gráficos, tabelas e quadros devem estar acompanhados de título explicativo, a fim de compreender o significado dos dados reunidos.

Para reimpressão de fotografias, figuras, quadros, tabelas e gráficos extraídos de outros textos, devem ser indicados a fonte de referência e anexada a autorização da fonte ou do autor.

Todas as ilustrações devem estar no corpo do texto e em arquivos separados do texto. ARTIGOS INTERNACIONAIS

As línguas podem ser: inglês, espanhol, italiano ou francês (todos serão traduzidos para o português).

Os títulos de obras estrangeiras devem vir acompanhados da tradução em português, colocada entre parênteses.

As referências bibliográficas devem estar completas para que sejam reestruturadas pelo editor de acordo com a ABNT. AVALIAÇÃO DOS ARTIGOS

A aceitação será feita com base na originalidade, significância e contribuição científica. Os revisores farão comentários gerais sobre o trabalho e informarão se o mesmo deve ser publicado, rejeitado ou se poderá ser publicado realizando-se algumas correções pelo(s) autor(es). Quando nossos pareceristas sugerirem modificações, as mesmas serão encaminhadas ao autor principal que deverá devolver o manuscrito corrigido em até 20 dias. Em seguida, o mesmo será devolvido aos pareceristas, para verificarem se as sugestões foram acatadas.

Em caso de discordância entre os avaliadores, poderá ser solicitada uma terceira opinião.

Após este processo, o(s) autor(es) serão avisados se o artigo será publicado ou não via e-mail.

Endereço: Revista Comunicação \& Educação - CCA-ECA-USP

Av. Prof. Lúcio Martins Rodrigues, 443, 2ำ andar (Secretaria CCA) CEP 05508-900 - Cidade Universitária - São Paulo/SP

Fone/fax: (+5511) 3091-4063 